\title{
Improved mapping of soil erodibility (K-Factor) in the Burdekin River catchment, Queensland, to aid landscape modelling
}

\author{
$\underline{\text { M.J. Pringle }}^{\text {a }}$, Payne, J.E. a ${ }^{\text {, Zund, P.R. }}{ }^{\text {, }}$, and Orton, T.G. ${ }^{\text {a,b }}$ \\ ${ }^{a}$ Department of Science, Information Technology, Innovation and the Arts, GPO Box 5078, Brisbane, \\ Queensland 4001 \\ ${ }^{b}$ Faculty of Agriculture and Environment, The University of Sydney, 1 Central Avenue, Australia Technology \\ Park, Eveleigh, New South Wales 2015 \\ Email: matthew.pringle@gld.gov.au
}

\begin{abstract}
Good-quality soil information is critical to the accuracy of models of environmental processes. In catchments that drain into Australia's Great Barrier Reef, process modelling is being used to improve understanding of the links between land-management, soil erosion, and sediment pollution of the marine environment. To underpin this modelling effort, we have been tasked with improving the available soil information for the Burdekin River catchment (the Reef catchment with the most severe land-degradation concerns) with a particular focus on those soil attributes that affect soil erodibility. We have applied geostatistical modelling techniques to the existing soil information to map $K$-factor of the Revised Universal Soil Loss Equation, averaged at a resolution of 1 ha.

The calculation of $K$-factor for any mapping pixel requires soil attributes for particle size fractions, organic carbon, structure and permeability for this pixel. Data for these attributes were sourced from existing analytical and morphological soil profile description sites, and were harmonized over the $0-5 \mathrm{~cm}$ and $5-15$ $\mathrm{cm}$ soil depth intervals (the first two intervals defined in the GlobalSoilMap.net project). Spatial surfaces of environmental covariates were calculated (16 terrain derivates and four gamma-ray spectroscopy covariates), and used to model and map the soil attribute data via a combination of random forest and geostatistical modelling methodology. The resultant spatial surfaces of soil attributes were mapped in rasters with a 1-ha block-averaged cell size. The modelling methods provide a probability distribution of the attribute uncertainty in each pixel. Values for attributes were then simulated and the $K$-factor formula applied, with this repeated to build a predictive distribution for $K$-factor.
\end{abstract}

Compared with existing maps of $K$-factor derived from polygonal data for ASRIS, the $K$-factor map produced using our method is continuous and relatively smooth. The benefits of the resulting $K$-factor map are:

- $\quad$ it is spatially continuous, which agrees with our general understanding of soil variability.

- the new maps have an improved spatial resolution of 1 ha.

- the new maps can be produced at any desired percentile. This is beneficial if the $K$-factor is to be used as an input to further modelling, as it will enhance sensitivity analysis of the subsequent model.

Keywords: Soil map, kriging, uncertainty, erosion, K-factor 
Pringle et al., Improved mapping of soil erodibility in the Burdekin River catchment, Queensland

\section{INTRODUCTION}

Soil information is a fundamental input to many models of environmental processes. For example, the Revised Universal Soil Loss Equation (RUSLE; Agricultural Research Service, 2010) models average annual soil loss (by water erosion) at a site, based on information related to soil, rainfall, topography, groundcover and management. The soil erodibility component of the RUSLE, conventionally known as ' $K$-factor' is determined using information on soil particle size, organic matter content, structure and permeability (Wischmeier et al., 1971), and has units of (Mg.ha.h) / (ha.MJ.mm) (Rosewell and Loch, 2002). The erosion estimates of the RUSLE can then be combined with mechanistic models of hydrological processes, to improve our understanding of, for example, the sediment loads of rivers. When soil information is expressed in the form of a map, $K$-factor can be mapped at the same scale (e.g. Lu et al., 2003). As soil scientists, we experience a perpetual call from modelers' for provision of improved (i.e. more accurate and/or finer scale) soil information. However, the maxim 'garbage in, garbage out' applies: the task of the soil scientist is to ensure that modelers' are aware of the uncertainty of the soil information used as model inputs. Uncertainty is useful for sensitivity analyses, and to assess issues such as error propagation.

In the last 5 years the GlobalSoilMap.net project (www.globalsoilmap.net) has been working to create global surfaces of key soil attributes, to agreed specifications. Four of the key specifications are: (i) depth intervals $0-0.05 \mathrm{~m}, 0.05-0.15 \mathrm{~m}, 0.15-0.30 \mathrm{~m}, 0.30-0.60 \mathrm{~m}, 0.60-1.00 \mathrm{~m}$, and $1.00-2.00 \mathrm{~m}$; (ii) spacing between grid nodes of 3 arc seconds ( $\sim 90 \mathrm{~m}$; analogous to the Shuttle Radar DEM); (iii) the estimate reported at each grid node will represent an average over a $100 \mathrm{~m} \times 100 \mathrm{~m}$ area about a node; (iv) the $90 \%$ confidence interval about the estimate in (iii) will also be reported. Specification (iv) is the estimate of the (local) uncertainty, mentioned above, that should be particularly appealing to simulation modelers'.

\subsection{The need for improved soil mapping in the catchments that drain into the Great Barrier Reef}

The Great Barrier Reef (GBR), off the coast of north-eastern Australia, is the largest system of coral reefs in the world, consisting of 3000 reefs over an area of 344,000 km (Great Barrier Reef Marine Park Authority, 2009). The unquestionable uniqueness of the GBR means that it must be protected from degradation, one source of which is river discharge that contains sediment, nutrients, and agricultural chemicals (Bainbridge et al., 2009; Brodie et al., 2010; Olley et al., 2013). Fabricius (2005) reviewed the effects of terrestrial runoff on coral reefs, and concluded that increased sedimentation has strong adverse effects on the growth and survival of adult coral populations. Bartley (2011) reviewed soil erosion-by-water in the Burdekin River basin, the Reef catchment with the most severe land-degradation concerns. She stated that the disparity between various modelled estimates of the sediment reaching the GBR is partly due to uncertainty in $K$-factor.

To address issues related to sediment, nutrient and pesticide delivery to the GBR, the Queensland and Australian governments have jointly funded the Reef Rescue and Reef Plan programmes to integrate data on management practices, catchment indicators, sediment loads, and the health of the GBR. The primary objective of the programmes are to measure and report on progress toward specified water-quality targets. The programmes involve monitoring and modelling a range of attributes at a range of scales, including management practices, water quality at the paddock, sub-catchment, catchment levels and in adjacent marine areas. The work undertaken in this paper seeks to address the knowledge deficits in soil-attribute information at sub-catchment scale.

Despite numerous soil surveys in the Burdekin River basin, we consider that only $5 \%$ of its area has soil information at a scale adequate to assess soil erodibility (i.e. surveys done at 1:100,000 scale or finer); the remainder is at scales too coarse (Figure 1). The GlobalSoilMap.net project offers a timely opportunity to revisit and improve the soil information of the Burdekin River basin in a quantitative manner for key attributes that influence soil erodibility.

\subsection{Aim}

The aim of this study was to produce a map of $K$-factor for the Burdekin River basin (herein simply 'the Burdekin'), Queensland, Australia, to the specifications of the GlobalSoilMap.net project. This will be done by producing, to the specifications of the GlobalSoilMap.net, raster surfaces of the soil attribute values used to determine $K$-factor, and then applying the relevant equations pixel-by-pixel. 


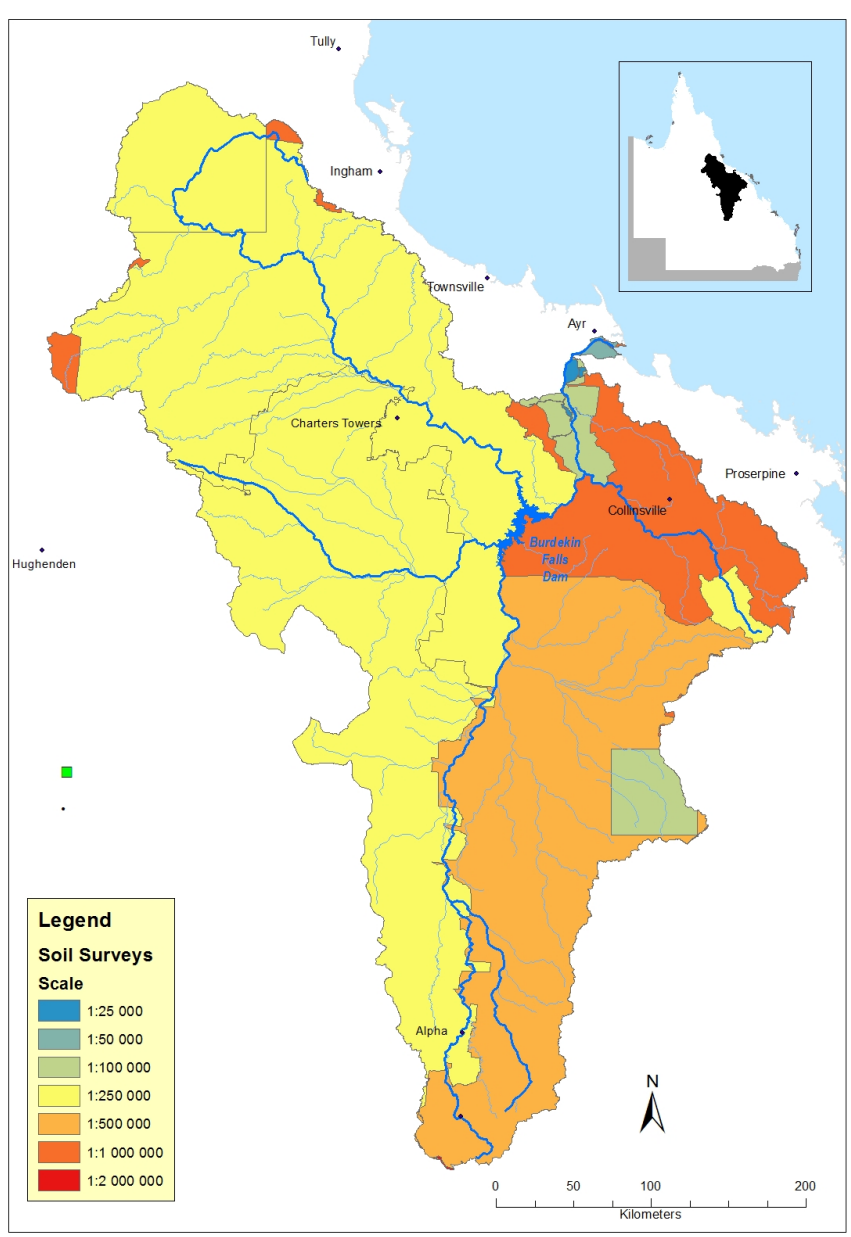

Figure 1. Scales of existing soil information in the Burdekin River basin, Queensland, Australia. The main drainage lines of the basin are indicated in blue. Fine-scale soil surveys $(1: 25,000)$ are typically used for land-capability assessments; broadest-scale soil surveys (1:2000000) are typically used for national resource inventory (Reid, 1988).

\section{METHODS}

There are four soil attributes required to compute $K$-factor: (Rosewell and Loch, 2002): surface particle-size (i.e. per cent clay, silt, fine sand, and coarse sand); surface organic matter (OM) (equivalent to per cent soil organic carbon $(\mathrm{OC}) \times 1.72$ ), surface structure (four grades) and profile permeability (six classes). Note that the grades/classes for structure and permeability used in the calculation of $K$-factor do not correspond with those generally used in soil survey in Australia, as defined by McDonald and Isbell (2009; herein termed the 'Yellow Book'). To enable the use of legacy soil survey data we matched the Yellow Book descriptions to surface structure grade and profile permeability class defined by Rosewell (1993) (Table 1).

Because soil was rarely sampled at the GlobalSoilMap.net depth intervals, the depth functions of the four particle sizes and OC were disaggregated at 0.01-m intervals using an equal-area spline (Bishop et al., 1999; Malone et al., 2009) then averaged over the appropriate interval. The depth function of structure grade was disaggregated using nearest neighbour interpolation, prior to averaging. The nearest neighbour interpolation was used to account for cases where data for some depth intervals were missing. Since structure grade is a categorical variable, the subsequent averaging took the form of calculating the modal structure grade within each GlobalSoilMap.net depth interval. These steps 'harmonised' the data for interpolation. Note that the $K$ factor only relates to the top $0.15 \mathrm{~m}$ of the soil profile (i.e. the surface soil), so the deeper intervals of GlobalSoilMap.net are not relevant to this study. Details of the number of samples available for each attribute at depth intervals of $0-0.05 \mathrm{~m}$ and $0.05-0.15 \mathrm{~m}$ are given in Table 2 . The number of observations for permeability did not change with depth because they related to the entire profile.

Our task was to fit a statistical model to each of the seven attributes in Table 2, to enable their prediction on a 3 -arcsecond grid across the Burdekin, at a resolution of 1 ha. The explanatory variables at our disposal for the 
Pringle et al., Improved mapping of soil erodibility in the Burdekin River catchment, Queensland

Table 1. Correspondence between RUSLE $K$-factor inputs and 'Yellow Book' grades/classes (McDonald and Isbell, 2009) for: (a) structure; and, (b) permeability.

\begin{tabular}{|l|l|l|}
\hline Grade/ Class & RUSLE Description & 'Yellow Book' description \\
\hline (a) Structure & & \\
\hline 1 & Very fine granular $(<1 \mathrm{~mm})$ & NA \\
\hline 2 & Fine granular $(1-2 \mathrm{~mm})$ & $<2 \mathrm{~mm}$ peds \\
\hline 3 & Medium or course granular $(2-10 \mathrm{~mm})$ & $2-10 \mathrm{~mm}$ peds \\
\hline 4 & Blocky, platy or massive $($ coherent $)$ & $\begin{array}{l}\text { Blocky (angular or subangular), platy or } \\
\text { columnar peds, or massive soil }\end{array}$ \\
\hline$(\mathrm{b})$ Permeability & & \\
\hline 1 & Rapid $(>3120 \mathrm{~mm} /$ day $)$ & NA \\
\hline 2 & Moderate to rapid $(1440-3120 \mathrm{~mm} /$ day $)$ & Highly permeable $(>500 \mathrm{~mm} /$ day $)$ \\
\hline 3 & Moderate $(480-1440 \mathrm{~mm} /$ day $)$ & NA \\
\hline 4 & Slow to moderate $(100-480 \mathrm{~mm} /$ day) & Moderately permeable $(50-500 \mathrm{~mm} /$ day $)$ \\
\hline 5 & Slow $(25-100 \mathrm{~mm} /$ day $)$ & Slowly permeable $(5-50 \mathrm{~mm} /$ day $)$ \\
\hline 6 & Very slow $(<25 \mathrm{~mm} /$ day $)$ & Very slowly permeable $(<5 \mathrm{~mm} /$ day $)$ \\
\hline
\end{tabular}

Table 2. Numbers of observations associated with each variable.

\begin{tabular}{|l|l|l|l|l|}
\hline Depth interval (m) & $\begin{array}{l}\text { Particle size analysis } \\
\text { (clay, silt, course and } \\
\text { fine sand) }\end{array}$ & OC & Structure grade & Permeability class \\
\hline $0-0.05$ & 656 & 718 & 10778 & \multirow{2}{*}{6102} \\
\hline $0.05-0.15$ & 643 & 363 & 10031 & \\
\hline
\end{tabular}

model were derived by terrain analysis of the 1-second SRTM-DEMH Derived Hydrological Digital Elevation Model (Farr et al., 2007; 16 variables in total), and a further four variables derived through gammaray spectrometry (Wilford, 2012).

The model used in each case was a random forest (Breiman, 2001). This approach was attractive because it could: (i) mine the data for relations in an automated manner; (ii) deal implicitly with non-linearity and interactions between variables; and (iii) be applied to both the continuous and categorical response variables. For structure and permeability, the probability of each grade/class, as predicted by the random forest, was mapped across the catchment on a $25-\mathrm{m}$ grid, and the probabilities averaged over 1-ha about each 3arcsecond grid node. For particle size and OC we combined the predictions of the random forest with kriging of the residuals of the random forest ('regression kriging' (Odeh et al., 1994; McBratney et al., 2003). Kriging was done on 1-ha blocks about each 3-arcsecond grid node. The predictive distribution for the mean particle size and OC at each pixel was associated with a $90 \%$ confidence interval.

We used the formulae of Lu et al. (2003) - specifically their equations (3) and (4) - to compute $K$-factor from the maps of the soil attributes. (Although, as noted above, we converted OC to OM using a multiplication factor of 1.72, whereas $\mathrm{Lu}$ et al. (2003) used a multiplication factor of 2.) At each pixel we computed a probability distribution function for $K$-factor by simulating from the predictive distributions of the inputs to the equations: for particle size and OC, we drew 10000 random values from the Gaussian distribution; for structure and permeability, we drew 10000 random values from the multinomial distribution. The resulting map of $K$-factor was visually compared with the existing map of $K$-factor for the Burdekin, derived from ASRIS polygons (www.asris.csiro.au/).

\section{RESULTS}

Maps of particle size, OC, and RUSLE permeability and structure are shown for the northern part of the Burdekin in Figure 2. Values for fine sand, coarse sand and OC decrease with depth, as expected. Also expected was the relative uniformity of RUSLE structure (almost all grade 4). Permeability is dominated by class 4 . The ASRIS map of $K$-factor (Figure 3) has a blocky appearance, due to its vector-based origin. Polygons in the vicinity of the Burdekin River (indicated in blue) are finely-resolved, with relatively small values of $K$-factor seen adjacent to some relatively large values. The 'new' maps of $K$-factor, based on GlobalSoilMap.net specifications, are continuous and relatively smooth, with no exaggerated effect of the drainage line. The difference between the $5^{\text {th }}$ percentile and the $95^{\text {th }}$ percentile was generally about 0.025 
units over the study area: values for the $5^{\text {th }}$ percentile suggest the soil could be classified as having 'moderate' to 'high' erodibility (Rosewell and Loch, 2002), while those for the $95^{\text {th }}$ percentile are 'high' to 'very high'.
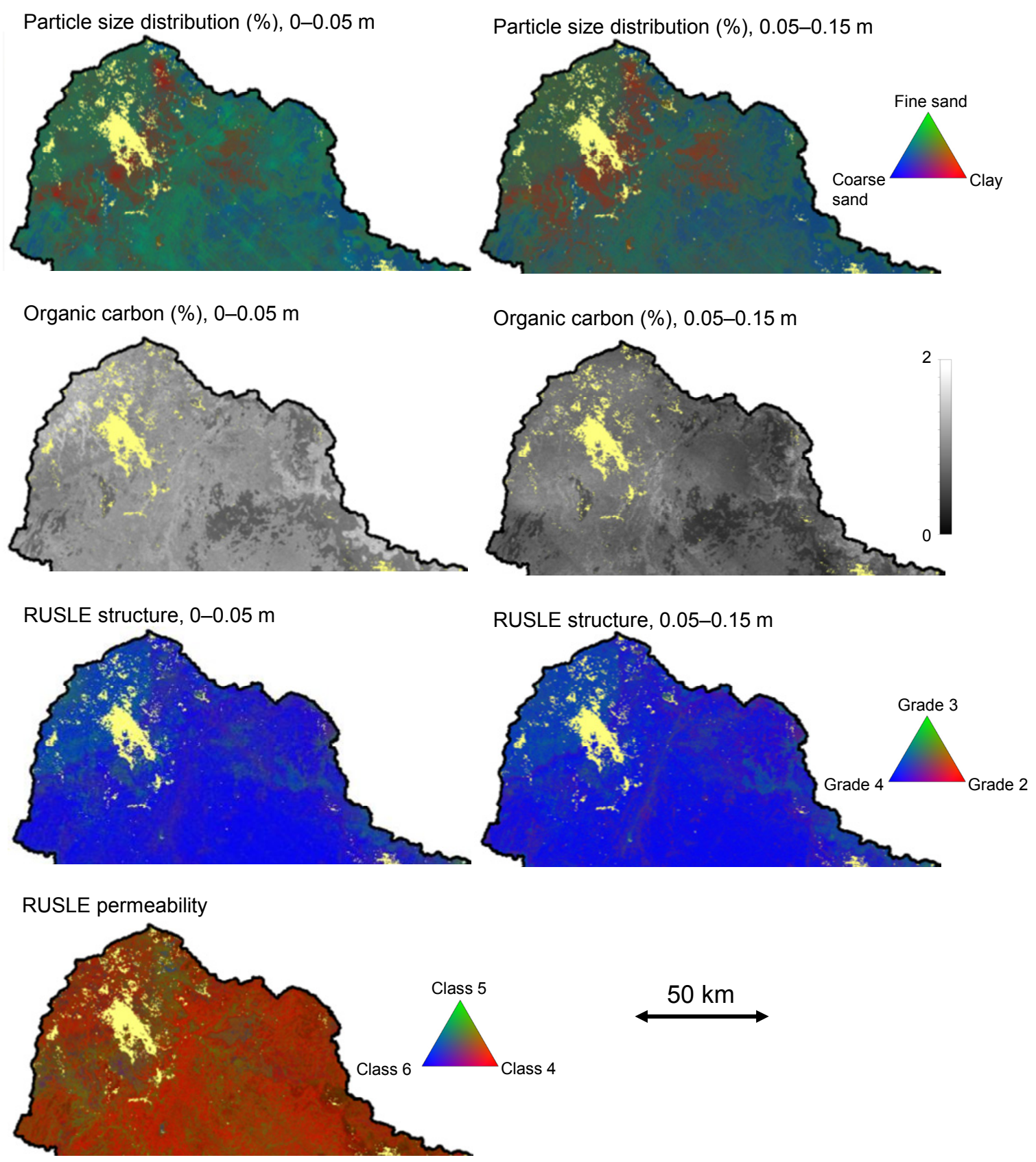

Figure 2. Soil attributes required for determination of soil erodibility ( ' $K$-factor'), for the northern part of the Burdekin catchment. Each attribute has been modelled from observed point data to the specifications of GlobalSoilMap.net. The yellow colour in each map indicates where the soil depth is $<0.15 \mathrm{~m}$ and therefore insufficient to compute $K$-factor. Each map is associated with layers that describe the uncertainty about the predicted mean (not shown). 

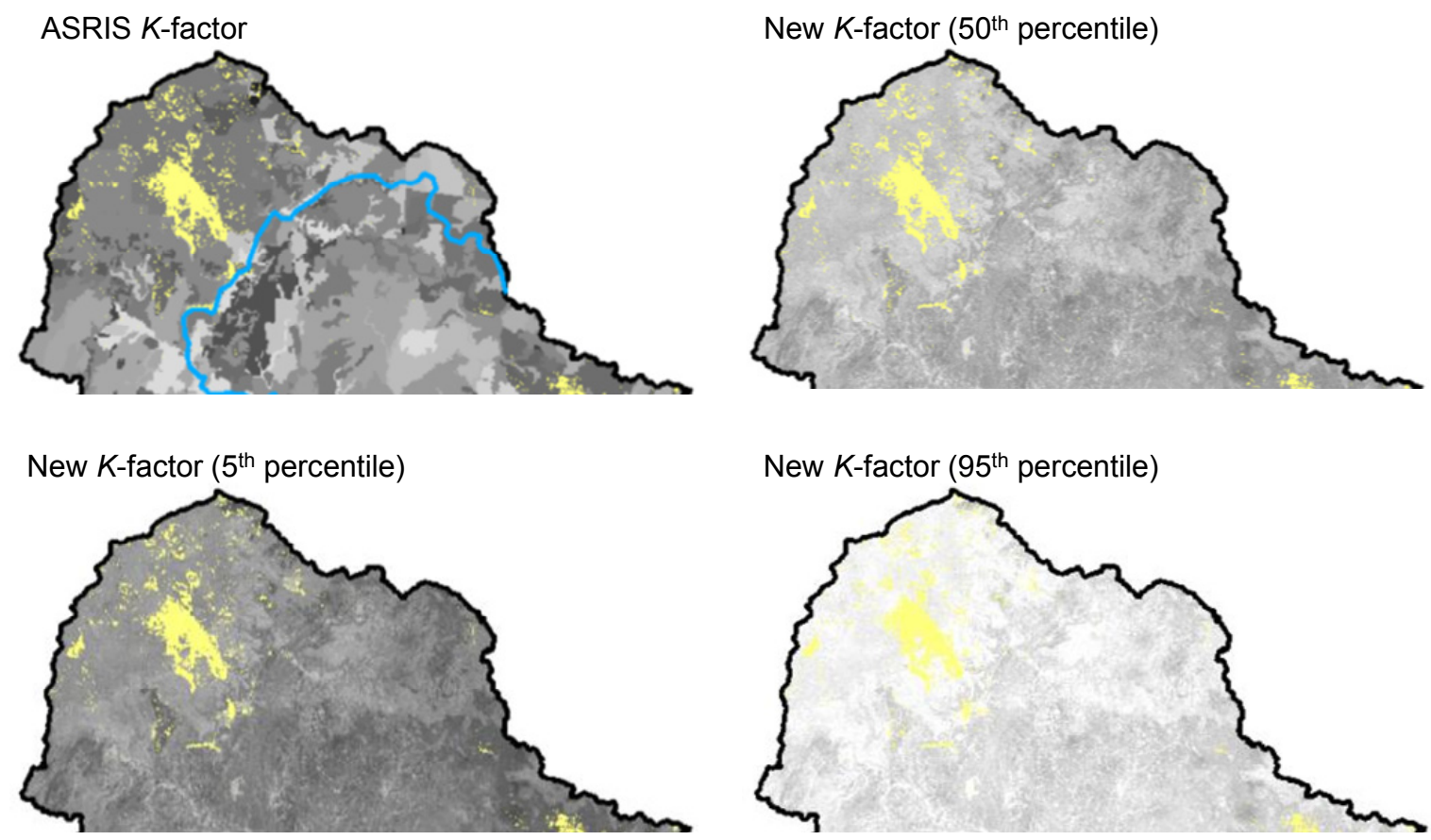

0

Figure 3. Soil erodibility (the ' $K$-factor'), computed in two ways: (i) with ASRIS polygons (the best publically available soil knowledge); and (ii) using (point-scale) soil information that has first been interpolated to the specification of GlobalSoilMap.net. Note that the latter yields a continuous surface at any desired percentile. The yellow colour in each map indicates where the soil depth is $<0.15 \mathrm{~m}$ and therefore insufficient to compute the $K$-factor. The blue line on the ASRIS-based map indicates the Burdekin River.

\section{CONCLUSIONS}

$K$-factor was noted by Bartley (2011) to confer a large degree of uncertainty on soil-erosion modelling in the Burdekin. Is the 'new' way of mapping $K$-factor an improvement on existing knowledge? We believe so. At present we have made no more than a visual comparison between the two methods, but there are three arguments for why the new way should be preferred. First, the resulting map of $K$-factor is spatially continuous, which agrees with our general understanding of soil variability (Webster and Oliver, 2001). Second, the new maps have a defined spatial resolution of 1 ha, and should be sufficiently fine to satisfy the modelling community for some time. Third, the new maps can be made at any desired percentile. This is beneficial if $K$-factor is to be used as an input to further modelling, as it will enhance the sensitivity analysis performed on the subsequent model.

There are, however, issues to be resolved. For example, the presence of coarse fragments ( $>2 \mathrm{~mm})$ in a soil profile necessitates a change to the RUSLE permeability class (Rosewell and Loch, 2002), but we have made no attempt to account for this yet. The other issue is the scale of application of K-factor. In this study we conveniently applied $K$-factor to the aggregated input variables at the mapping resolution of 1 ha. Heuvelink and Pebesma (1999) reasoned that, when a model is non-linear (as the equations for the $K$-factor are), the input data need to be at the stated scale of the model. As $K$-factor should in theory be applied to a soil unit of reasonably uniform soil properties, the smaller the unit of application of the $K$-factor equation, the better. Therefore, it could be argued that it would make more sense to apply $K$-factor after point-support interpolation of the input variables to a fine-grid (perhaps a $25-\mathrm{m}$ grid), before aggregation of the $K$-factors to the required mapping scale (1-ha block averages). We applied the $K$-factor equation after interpolation and aggregation to the 1-ha scale, since maps of the $K$-factor inputs at the 1-ha aggregated scale also provide useful information for the GlobalSoilMap.net project. However, comparison with an approach that applies the $K$-factor equation after point-support interpolation but before aggregation to 1-ha blocks provides scope for further work. 
Pringle et al., Improved mapping of soil erodibility in the Burdekin River catchment, Queensland

We also raise another issue relating to the order in which calculations are performed. We interpolated and aggregated the input variables to the required resolution before applying the $K$-factor equation. However, an alternative approach is to begin by calculating $K$-factor directly from the data, wherever the data at a site contain measurements of all four input variables. The calculated $K$-factors for these data sites could then be interpolated and aggregated to the required resolution. This approach could be summarized as a 'calculate- $K$ factor-then- interpolate' approach, as opposed to the 'interpolate-then-calculate- $K$-factor' approach that we applied. A significant drawback of the calculate-then-interpolate approach is the lack of sites with data for all four input variables; data from sites where three or fewer of the four inputs were measured would not be used, resulting in a loss of information. This lack of collocated data is by no means specific to our study, since the availability of data in the Burdekin is relatively good compared with much of Australia's rangelands. We adopted the interpolate-then-calculate approach to make the best use of the available dataset, although the comparison with the calculate-then-model alternative would provide another interesting future study.

\section{REFERENCES}

Agricultural Research Service (2010). Revised Universal Soil Loss Equation 2 - Overview of RUSLE2. At: http://www.ars.usda.gov/Research/docs.htm?docid=6010 [accessed 5 July 2013]

Bainbridge, Z.T., J.E. Brodie, J.W., Faithful, D.A. Sydes, and S.E. Lewis (2009). Identifying the land-based sources of suspended sediments, nutrients and pesticides discharged to the Great Barrier Reef from the Tully-Murray Basin, Queensland, Australia. Marine and Freshwater Research, 60, 1081-1090.

Bartley, R. (2011). Sediment sources and grazing land management impacts in the Burdekin catchment: a review of existing research and projection of future research needs. Report to the Queensland Department of Natural Resources (Reef Protection Unit). CSIRO, Australia.

Bishop, T.F.A., A.B. McBratney, and G.M. Laslett (1999). Modelling soil attribute depth function with equal-area quadratic smoothing splines. Geoderma, 91, 27-45.

Breiman, L. (2001). Random forests. Machine Learning, 45, 5-32.

Brodie, J., T. Schroeder, K. Rohde, J. Faithful, B. Masters, A. Dekker, V. Brando, and M. Maughan (2010). Dispersal of suspended sediments and nutrients in the Great Barrier Reef lagoon during river-discharge events: conclusions from satellite remote-sensing and concurrent flood-plume sampling. Marine and Freshwater Research, 61, 651-664.

Fabricius, K. (2005). Effects of terrestrial runoff on the ecology of corals and coral reefs: review and synthesis. Marine Pollution Bulletin, 50, 125-146.

Farr, T.G., P.A. Rosen, E. Caro, R. Crippen, R. Duren, S. Hensley, M. Kobrick, et al. (2007). The Shuttle Radar Topography Mission. Reviews of Geophysics, 45, RG2004, doi:10.1029/2005RG000183.

Great Barrier Reef Marine Park Authority (2009). Great Barrier Reef Outlook Report, 2009. Great Barrier Reef Marine Park Authority, Townsville. At: http://www.gbrmpa.gov.au/_data/assets/pdf_file/ 0018/3843/OutlookReport_Full.pdf [accessed 5 July 2013].

Heuvelink, G.B.M., and E.J. Pebesma (1999). Spatial aggregation and soil process modelling. Geoderma, 89, 47-65.

Lu, H., I.P. Prosser, C.J. Moran, J.C. Gallant, G. Priestley, and J.G. Stevenson (2003). Predicting sheetwash and rill erosion over the Australian continent. Australian Journal of Soil Research, 41, 1037-1062.

Malone, B.P., A.B. McBratney, B. Minasny, and G.M. Laslett (2009). Mapping continuous depth functions of soil carbon storage and available water capacity. Geoderma, 154, 138-152.

McBratney, A.B., M.L. Mendonça Santos, and B. Minasny (2003). On digital soil mapping. Geoderma, 117, 3-52.

McDonald, R.C., and R.F. Isbell (2009). Soil Profile. In: Australian Soil and Land Survey Field Handbook (3 $3^{\text {rd }}$ edn) (National Committee and Soil and Terrain). CSIRO Publishing, Melbourne, Australia. pp. 147-204.

Odeh, I.O.A., A.B. McBratney, and D.J. Chittleborough (1994). Spatial prediction of soil properties from landform attributes from a digital elevation model. Geoderma, 63, 197-214.

Olley, J., A. Brooks, J. Spencer, T. Pietsch, and D. Borombovits (2013). Subsoil erosion dominates the supply of fine sediments to rivers draining into Princess Charlotte Bay, Australia. Journal of Environmental Radioactivity, 124, 121129.

Reid, R.E. (1988). Soil survey specifications. In: Australian Soil and Land Survey Handbook (edited by R.H. Gunn, J.A. Beattie, R.E. Reid, and R.H.M. van de Graaff). Inkata Press, Melbourne, Australia. pp 60-72.

Rosewell, C.J. (1993). SOILOSS - A program to assist in the selection of management practices to reduce erosion. Technical Handbook No. 11 ( $2^{\text {nd }}$. Ed.). Soil Conservation Service of New South Wales, Sydney.

Rosewell, C.J., and R.J. Loch (2002). Estimation of the RUSLE soil erodibility factor. In: Soil Physical Measurement and Interpretation for Land Evaluation (edited by N. McKenzie, K. Coughlan, and H. Cresswell). CSIRO Publishing, Melbourne, Australia. pp. 361-369.

Webster, R., and M.A. Oliver (2001). Geostatistics for Environmental Scientists. John Wiley \& Sons Ltd, Chichester.

Wilford, J. (2012). A weathering intensity index for the Australian continent using airborne gamma-ray spectrometry and digitial terrain analysis. Geoderma, 183-184, 124-142.

Wischmeier, W.H., C.B. Johnson, and B.V. Cross (1971). A soil erodibility nomograph for farmland and construction sites. Journal of Soil and Water Conservation, 26, 189-193. 